Original Research Paper

\title{
Potential Radiological Impacts of Phosphate Fertilizers Brands used in Southeast, Nigeria
}

\author{
${ }^{1}$ Kenneth K. Agwu, ${ }^{1}$ Mark C. Okeji and ${ }^{2}$ Paschal Tchokossa \\ ${ }^{1}$ Department of Medical Radiography and Radiological Sciences, \\ Faculty of Health Sciences and Technology, University of Nigeria, Enugu Campus, Nigeria \\ ${ }^{2}$ Department of Physics, Obafemi Awolowo University, Ile-Ife, Osun State, Nigeria
}

Article history

Received: 08-02-2017

Revised: 03-05-2017

Accepted: 11-05-2017

Corresponding Author:

Mark C. Okeji

Department of Medical

Radiography and Radiological

Sciences, Faculty of Health

Sciences and Technology,

University of Nigeria, Enugu

Campus, Nigeria

Email: markokeji@yahoo.com

\begin{abstract}
The radionuclides present in phosphate fertilizers used in Southeast Nigeria were identified and their activity concentration determined to assess the potential radiological impact on the environment due to fertilizer applications in agricultural farm lands. The radioactivity concentration of ${ }^{226} \mathrm{Ra},{ }^{232} \mathrm{Th}$ and ${ }^{40} \mathrm{~K}$ in the fertilizer samples range from $13.22 \pm 1.83$ to $87.37 \pm 8.98 \mathrm{Bqkg}^{-1}$ for ${ }^{226} \mathrm{Ra}$ (mean: $31.71 \pm 5.4 \mathrm{Bqkg}^{-1}$ ), $0.78 \pm 0.07$ to $47.65 \pm 6.05 \mathrm{Bqkg}^{-1}$ for ${ }^{232} \mathrm{Th}$ (mean: $10.88 \pm 3.06$ ) and $575.07 \pm 18.08$ to $1234.80 \pm 36.61 \mathrm{Bqkg}^{-1}$ for ${ }^{40} \mathrm{~K}$ (mean $876.91 \pm 20.03 \mathrm{Bqkg}^{-1}$ ). The mean activity concentrations of the natural radionuclides of ${ }^{226} \mathrm{Ra}$ and ${ }^{232} \mathrm{Th}$ in the superphosphate fertilizer formulation were found to be above the world's average. This will have potential health impact on humans if the fertilizers are applied in crops cultivation. The absorbed dose range from $31.01 \pm 0.03$ to $75.11 \pm 0.49$ $\mathrm{nGyh}^{-1}$ (mean: $68.66 \pm 0.35 \mathrm{nGyh}^{-1}$ ). The super phosphate brand of fertilizer with the highest value of activity concentration has its value of annual effective dose as $0.08 \mu \mathrm{SvGyh}^{-1}$.
\end{abstract}

Keywords: Phosphate Fertilizer, Radioactivity, Radiological Impact, Nigeria

\section{Introduction}

Food is one of the cardinal needs of man. The increasing world population has become a threat to the global food security. There is, therefore, the need to increase food production to ensure food security for the growing world population. Chemical fertilizers are employed in agriculture to reclaim land and enhance crop yield (Alharbi, 2013). Chemical fertilizers are chemical compounds that provide necessary elements and nutrients to the plants (Uosif et al., 2014). Nitrogen, phosphorus and potassium are essential nutrients necessary for plant growth and therefore form major raw materials for the production of chemical fertilizer. The application of phosphate fertilizer globally for increased crop production and land reclamation has risen to more than 30 million tons annually (El-Taher and Althoyaib, 2012).

Natural radioactivity of mainly Uranium- $238\left({ }^{238} \mathrm{U}\right)$, Thorium-232 $\left({ }^{23} \mathrm{Th}\right)$ and Potassium-40 $\left({ }^{40} \mathrm{~K}\right)$ seen in phosphate fertilizers emanate from the phosphate ore, (due to geological reasons) which is the main raw material used for phosphate fertilizer production
(UNSCEAR, 1988). Due to the presence of these radionuclides and their decay products in the phosphate ore, they are present in fertilizer products and wastes associated with it (Erdem et al., 1995; Marovic and Sencar, 1995; Uosif et al., 2014). These radionuclides are inadvertently transferred to humans through the food chain (Okeji et al., 2012). The ammonium based fertilizer brands have been shown by Uosif et al. (2014) to contain minimal amount of radioactivity and hence was not included in this study. The natural radioactivity present in phosphate fertilizers used by farmers in the five Southeastern States of Nigeria has not been established to the best of the researchers' knowledge. There is, therefore, need for this study to estimate the possible contribution to environmental radioactivity from the application of phosphate fertilizers to farmlands in this region.

\section{Materials and Methods}

Eight different formulations of phosphate fertilizers commonly used by farmers in the Southeastern Nigeria were collected from the open market and fertilizer 
warehouses in each of the five Southeastern States. They comprised seven solid and one liquid brand. Five samples each, weighing $500 \mathrm{gm}$, of the eight popular formulations were collected from the five states in the region making a total of 40 samples. National Fertilizer Company of Nigeria (NAFCON), Kaduna, manufactured four solid formulations $\left(\mathrm{K}_{1}, \mathrm{~K}_{2} \mathrm{~K}_{3}\right.$ and $\left.\mathrm{K}_{4}\right)$. Three other solid formulations were imported brands marketed by Golden investments (G1, G2 and G3). A Liquid Formulation (LF) was manufactured by Green Plant International, Jos, Nigeria (Table 1). The solid samples were dried in open oven to remove moistures. The dried samples were pulverized and passed through a $2 \mathrm{~mm}$ sieve. Marinelli beakers designed to fit into the sodium iodide gamma spectrometer counting chamber were thoroughly washed in $0.1 \mathrm{~m}$ hydrochloric acid. They were then rinsed in distilled water and dried to avoid contamination. The empty beakers were weighed before the fertilizer samples were packed and hermetically sealed. The samples were weighed again to obtain the net weight of the fertilizer samples. The sealed samples were left for 28 days to allow short-lived radionuclides of ${ }^{238} \mathrm{U}$ and ${ }^{232} \mathrm{Th}$ to attain secular equilibrium.

\section{Gamma Spectrometric Analysis}

The activity counting was carried out using Sodium iodide (NaI) gamma-spectrometric system. The system consists of $76 \times 76 \mathrm{~mm} \mathrm{NaI}(\mathrm{Tl})$ detector manufactured by Canberra Inc. connected to a multichannel analyzer through a preamplifier base and interphased to an IBM personal computer. The detector has a resolution of about $8 \%$ at $662 \mathrm{kev}$ for ${ }^{137} \mathrm{Cs}$. This value is capable of distinguishing the gamma ray energies likely to be encountered in the measurement of the samples. Energy calibration was carried out using standard source from IAEA with photo peak of known energies in the range of 200 to $2500 \mathrm{kev}$. Efficiency calibration was achieved using standard reference source (IAEA, 1989) whose energies and activities are known. Each sample was counted for $36000 \mathrm{sec}$. $(10 \mathrm{~h})$ and the data acquired automatically by SAMPO 90 software program. The software searches for the peak, evaluates the peak position in the energy spectrum, identifies the radionuclide by means of a radionuclide library. It calculates the net peak areas after subtracting the background count. The activity concentration in selected units is subsequently displayed. The empty Marinelli beaker was counted for the same period of time and subtracted from the values.

\section{Results and Discussion}

The radioactivity concentration of ${ }^{226} \mathrm{Ra},{ }^{232} \mathrm{Th}$ and ${ }^{40} \mathrm{~K}$ in the fertilizer samples range from $13.22 \pm 1.83$ to
87.37 $\pm 8.98 \mathrm{Bqkg}^{-1}$ for ${ }^{226} \mathrm{Ra}$ (mean: $31.71 \pm 5.4 \mathrm{Bqkg}^{-1}$ ), $0.78 \pm 0.07$ to $47.65 \pm 6.05 \mathrm{Bqkg}^{-1}$ for ${ }^{232} \mathrm{Th}$ (mean: $10.88 \pm 3.06)$ and $575.07 \pm 18.08$ to $1234.80 \pm 36.61 \mathrm{Bqkg}^{-1}$ for ${ }^{40} \mathrm{~K}$ (mean $876.91 \pm 20.03 \mathrm{Bqkg}^{-1}$ (Table 2).

The super phosphate formulation $\left(\mathrm{K}_{1}\right)$ from NAFCON has the highest mean activity concentration of ${ }^{226} \mathrm{Ra} \quad\left(87.37 \pm 8.98 \quad \mathrm{Bqkg}^{-1}\right)$ and ${ }^{232} \mathrm{Th} \quad(47.65 \pm 6.05$ $\left.\mathrm{Bqkg}^{-1}\right)$. These values are higher than the world's average value of for ${ }^{226} \mathrm{Ra}$ and $35 \mathrm{Bqkg}^{-1}\left({ }^{232} \mathrm{Th}\right)$ and 35 $\mathrm{Bqkg}^{-1}$ in normal soil samples (UNSCEAR, 2000). The activity concentration of ${ }^{40} \mathrm{~K}$ in the super phosphate brand $(165.62 \pm 4.98)$ is however below the world's average of $400 \mathrm{Bqkg}^{-1}$. The other seven formulations have their activity concentration of ${ }^{226} \mathrm{Ra}$ and ${ }^{232} \mathrm{Th}$ below the world's average of $35 \mathrm{Bqkg}^{-1}$ (Table 2) but their activity concentration of ${ }^{40} \mathrm{~K}$ were higher than the world's average of $400 \mathrm{Bqkg}^{-1}$. The high activity concentration of ${ }^{226} \mathrm{Ra}$ in the super phosphate formulation in our study is similar to the studies by Ahmed and El-Arabi, 2005; Khater and Al-Sewaidan, 2008; Chauhan et al., 2013; El-Taher and Mohamed, 2013; Uosif et al., 2014), (Table 3). However our value of $87.37 \pm 8.98 \mathrm{Bqkg}^{-1}$ for ${ }^{226} \mathrm{Ra}$ is the least. The variation in the values of the activity concentration may be due to the source of the raw material (phosphate ore) used in the formulation.

There was linear relationship between the ratio of phosphate in the fertilizer formulations and the activity concentration of ${ }^{238} \mathrm{U}(\mathrm{r}=0.95)$. No anthropogenic radionuclide was identified.

The superphosphate formulation has the potential of redistributing the Natural Occurring Radionuclides (NORM) through agricultural farming activities. These NORM will be absorbed by plants and through the food chain pose radiological risk to human (Rehman et al., 2006; Okeji et al., 2012).

\section{Absorbed Dose Rate in Air}

The absorbed does rate in air at $1 \mathrm{~m}$ above the ground due to NORM of ${ }^{226} \mathrm{Ra},{ }^{232} \mathrm{Th}$ an ${ }^{40} \mathrm{~K}$ were calculated based on the UNSCEAR (2000) model:

$$
D=0.462 A U+0.60 A T h+0.0417 A k
$$

where, $A_{U}, A_{T h}$ and $\mathrm{AK}$ are the activity concentrations of ${ }^{226} \mathrm{Ra}$, ${ }^{232} \mathrm{Th}$ and ${ }^{40} \mathrm{~K}$ (in $\mathrm{Bqkg}^{-1}$ ) respectively. The values of absorbed dose rate from our study range from $31.01 \pm 0.03$ to $75.11 \pm 0.49 \mathrm{nGyh}^{-1}$ (mean: 68.66 \pm 0.35 $\mathrm{nGyh}^{-1}$.) The range of values from our study is within the world's normal range of $18-93 \mathrm{nGyh}^{-1}$. However the mean value from our study was higher than the world average of $59 \mathrm{nGyh}^{-1}$ (UNSCEAR, 2000). The rest of the fertilizer formulations studied had their absorbed dose rates less than the world's average and therefore posses no radiological risk for the populations. 
Table 1. Phosphate fertilizer commonly used in Southeastern Nigeria

\begin{tabular}{llll}
\hline Code & Types o fertilizer & Formulation & Manufacturer \\
\hline $\mathrm{K}_{1}$ & SSP & Single super-phosphate & NAFCON \\
$\mathrm{K}_{2}$ & NPK & $20: 10: 5$ & NAFCON \\
$\mathrm{K}_{3}$ & NPK & $20: 10: 10$ & NAFCON \\
$\mathrm{K}_{4}$ & NPK & $20: 10: 17$ & NAFCON \\
$\mathrm{G}_{1}$ & NPK & $15: 15: 15$ & Golden investment (Imported) \\
$\mathrm{G}_{2}$ & NPK & $12: 12: 17$ & Golden investment (Imported) \\
$\mathrm{G}_{3}$ & NPK & $20: 10: 10$ & Golden investment (Imported) \\
$\mathrm{LF}$ & NPK & $8 \%$ Phosphate & Green Pant, Jos \\
\hline
\end{tabular}

Table 2. Activity of radionuclide's in the fertilizer A

\begin{tabular}{llll} 
& & Concentration & \\
Code & Activity & ${ }^{226} \mathrm{Ra}$ & ${ }^{232} \mathrm{Th}$ \\
\hline $\mathrm{K}_{1}$ & $87.37 \pm 8.98$ & $47.65 \pm 6.05$ & $165.62 \pm 4.98$ \\
$\mathrm{~K}_{2}$ & $\mathrm{BDL}$ & $0.78 \pm 0.07$ & $726.51 \pm 23.75$ \\
$\mathrm{~K}_{3}$ & $\mathrm{BDL}$ & $0.78 \pm 0.08$ & $1128.22 \pm 35.24$ \\
$\mathrm{~K}_{4}$ & $17.82 \pm 2.28$ & $1.72 \pm 0.08$ & $1088.88 \pm 32.19$ \\
$\mathrm{G}_{1}$ & $28.29 \pm 3.60$ & $7.51 \pm 0.26$ & $1234.26 \pm 37.33$ \\
$\mathrm{G}_{2}$ & $19.36 \pm 2.47$ & $11.05 \pm 0.35$ & $1234.80 \pm 36.16$ \\
$\mathrm{G}_{3}$ & $24.23 \pm 3.12$ & $6.81 \pm 0.28$ & $861.94 \pm 26.30$ \\
$\mathrm{LG}_{4}$ & $13.22 \pm 1.83$ & $10.81 \pm 2.86$ & $575.07 \pm 18.08$ \\
Range & $13.22 \pm 1.83$ to & $0.78 \pm 0.07$ to & $575.07 \pm 18.08$ to \\
& $87.37 \pm 8.98$ & $47.65 \pm 6.05$ & $1234.80 \pm 36.61$ \\
Mean & $31.71 \pm 5.41$ & $10.88 \pm 3.06$ & $876.91 \pm 20.02$ \\
\hline BDL $: \mathrm{Ben}$
\end{tabular}

BDL: Below detection level

Table 3. Comparative mean radioactivity concentration of ${ }^{226} \mathrm{Ra}^{232} \mathrm{Th}$ and ${ }^{40} \mathrm{~K}$ in super phosphate fertilizer samples from other countries

\begin{tabular}{llrrrl}
\hline Country & Fertilizer & ${ }^{226} \mathrm{Ra}$ & \multicolumn{1}{c}{${ }^{232} \mathrm{Th}$} & \multicolumn{1}{c}{${ }^{40} \mathrm{~K}$} & References \\
\hline Egypt & SSP & 336.0 & 66.70 & 4.0 & Ahmed and El-Arabi (2005) \\
Pakistan & SSP & 556.0 & 49.70 & 221.0 & Khater and Al-Sewaidan (2008) \\
India & SSP & 52.7 & 7.00 & 87.0 & Chauhan et al. (2013) \\
Saudi Arabia & SSP & 55.2 & 8.86 & 553.0 & El-Taher and Mohamed (2013) \\
Nigeria (Southeast) SSP & & 31.7 & 10.90 & 876.9 & Present study \\
\hline
\end{tabular}

\section{Annual Effective Dose Rate}

To estimate the annual effective dose rates, the product of absorbed dose, conversion coefficient (0.7 $\mu \mathrm{SvGyh}^{-1}$ ) and outdoor occupancy factor (0.2) was obtained (UNSCELAR, 2000). The annual effective dose for the superphosphate formulation was $0.08 \mu \mathrm{SvGyh}^{-1}$. This value was the highest for all the fertilizer samples studied, of which value is less than $1 \mu \mathrm{Sv}$ recommended by ICRP-60 (1990). The fertilizer samples analyzed in this study do not pose any radiological hazard to the workers and the general population.

\section{Conclusion}

The radionuclide present in the chemical fertilizers used in Southeastern Nigerian and their activity concentrations were assessed using $\mathrm{NaI}(\mathrm{Tl})$ gamma spectrometry. The mean activity concentrations of the natural radionuclides of ${ }^{226} \mathrm{Ra}$ and ${ }^{232} \mathrm{Th}$ in the superphosphate fertilizer formulation were found to be above the world's average. However other phosphate fertilizer formulations studied have activity concentration of ${ }^{226} \mathrm{Ra}$ and ${ }^{232} \mathrm{Th}$ below the world average, but that of ${ }^{40} \mathrm{~K}$ above the world's average, though within the normal range seen in other countries. Only the absorbed dose rate in superphosphate fertilizer was higher than the world average.

\section{Author's Contributions:}

Kenneth K. Agwu: Participated in sample collection, coordinated the data-analysis and contributed to the writing of the manuscript.

Mark C. Okeji: Designed the research plan, participated in sample collection and all experiments, coordinated the data-analysis and contributed to the writing of the manuscript.

Paschal Tchokossa: Participated in all experiments and contributed to the writing of the manuscript.

\section{Conflict of Interest}

The author have no conflict of interest.

\section{References}

Ahmed, N.K. and A.G.M. El-Arabi, 2005. Natural radioactivity in farm soil and phosphate fertilizer and its environmental implications in Qena 
governorate, Upper Egypt. J. Environ. Radioactivity, 84: 51-64.

Alharbi, W.R., 2013. Natural radioactivity and dose assessment for brands of chemical fertilizers used in Saudi Arabia. J. Modern Phys., 4: 344-348.

Chauhan, P., R.P. Chauhan and M. Gupta, 2013. Estimation of naturally occurring radionuclides in fertilizers using gamma spectrometry and elemental analysis by XRF and XRD techniques. Microchem. J., 106: 73-78.

El-Taher, A. and S.S. Althoyaib, 2012. Natural radioactivity levels and heavy metals in chemical and organic fertilizers used in Kingdom of Saudi Arabia. Applied Radiat. Isotopes, 70: 290-295.

El-Taher, A. and M.A.K. Abdelhalim, 2013. Elemental analysis of phosphate fertilizer consumed in Saudi Arabia. Life Sci. J., 10: 701-708.

Erdem, E., N. TinKilic, V.T. Yilmaz, A. Uyanik and H. Olmez, 1995. Distribution of uranium in the production of Triple Superphosphate (TSP) fertilizer and phosphoric acid. Nutrient Cycl. Agro Ecosyst., 44: 129-131. DOI: 10.1007/BF00750802

IAEA, 1989. International Atomic Energy Agency. Measurements of Radionuclides in Food and the Environment. A Guide Book Technical Report Series No. 295 Vienna 27-28.

ICRP-60, 1990. Radiation protection: 1990 recommendations methods. Part 1 . Monoenergetic sources of natural radionuclides in the ground. GSF$\mathrm{B} 2 / 90$ of the International Commission on Radiological Protection, Pergamon Press.
Khater, A.E.M. and H.A. Al-Sewaidan, 2008. Radiation exposure due to agricultural uses of phosphate fertilizers. Radiat. Measur., 43: 1402-1407.

Marovic, G. and J. Sencar, 1995. ${ }^{226} \mathrm{Ra}$ and Possible water contamination due to phosphate fertilizer production. J. Radioanal Nucl. Chem., 200: 9-18.

Okeji, M.C., K.K. Agwu and F.U. Idigo, 2012. Assessment of natural radioactivity in phosphate ore, phosphogypsum and soil samples around a phosphate fertilizer plant in Nigeria. Bull. Environ. Contam. Toxicol., 89: 1078-1081.

Rehman, S., N. Imtiaz, M. Faheem and Matiullah, 2006. Determination of ${ }^{238} \mathrm{U}$ contents in ore samples using CR-39 based radon dosimeter disequilibrium case. Radiat. Measur., 41: 471- 476.

UNSCEAR, 1988. United nations scientific committee on the effects of atomic radiation. Report to the General Assembly with annexes, (United Nations Sales Publication, New York).

UNSCEAR, 2000. United nations scientific committee on the effects of atomic radiation. Report to the General Assembly with Scientific Annexes, (United Nations Sales Publication, New York).

Uosif, M.A.M., A.M.A. Mostafa, R. Elsaman and E. Moustafa, 2014. Natural radioactivity levels and radiological hazards indices of chemical fertilizers commonly used in upper Egypt. J. Radiat. Res. Applied Sci., 7: 430-437. 